\title{
Investigation of Natural Fibre Reinforced Cementitious Composite for Structural Retrofitting of Building Structures
}

\author{
Kai Tai WAN \\ Lecturer in Civil \\ Engineering \\ Brunel University London, \\ UK \\ KaiTai.Wan@brunel.ac.uk \\ Kai Tai Wan received his $\mathrm{PhD}$ in \\ Civil Engineering from the Hong \\ Kong University of Science and \\ Technology in 2005. His \\ expertise is in cementitious \\ composite and structural health \\ monitoring.
}

\author{
Javil Parris \\ Brunel University London, \\ UK \\ Bs14jrp@my.brunel.ac.uk
}

Javil Parris received MSc in Structural Engineering from Brunel University London in 2015.

\section{Summary}

Many masonry building structures are vulnerable to a seismic event. There are many structural retrofitting technologies available, such as glass/carbon fibre reinforced polymeric matrix composite. However, it is difficult to protect the polymeric matrix from fire in building structures. To fundamentally improve the fire resistance of retrofitting material, it can simply change the polymeric matrix to cement based matrix. This kind of composite is called fibre reinforced cementitious matrix (FRCM). It consists of high performance manmade fibre such as AR glass, carbon, basalt or Kevlar and it is extensively investigated by different researchers. It provides an excellent alternative for engineers to structural retrofit building structures for which fire is one of major design concerns. Ironically, most of the earthquake active zones are in the poorest region in the world because of constinuous attack by natural disasters. In those regions, the building structures are the most vulnerable to an extreme event such as earthquake and there is a need for structural retrofitting. Due to poor economic development of those regions, it is unaffordable to apply high performance manmade fibre to achieve the purpose. One practical solution is to develop a technically feasible, economically viable and environmentally sustainable is to replace high performance manmade fibre by locally available natural fibre in FRCM. A technical challenge is the durability of natural fibre in the high alkalinity environment of cementitious matrix. In this presentation, the effects of different treatment methods on sisal fibre as well as how to extract the mechanical and bond parameters of treated fibre from pull-out test under accelerated ageing test will be discussed.

Keywords:Fibre reinforced cementitious matrix, sisal fibre, pull-out test, bond parameters.

\section{Introduction}

There were tens of thousands of casualties in earthquakes due to the collapse of improperly designed and built residential buildings, especially in developing countries and poor regions, such as Haiti 2010, Indian Ocean 2004, Kashmir 2005 and Sichuan 2008. Fibre reinforced polymer (FRP) has been widely used to strengthen/retrofit reinforced concrete as well as masonry structures because of its excellent mechanical properties, high corrosive resistance, flexibility and ease of applications. However, there are several drawbacks of using FRP to retrofit building that include careful fire design, inapplicable on moist surface as well as incompatible thermal and mechanical properties to substrate materials. There is another promising alternative that simply replaces the polymeric matrix by cementitious matrix. This material is named fibre reinforced cementitious matrix (FRCM). The installation procedure is similar to nominal plastering work. There are existing guidelines available to design and construct FRCM [1,2]. It specifies the materials used and design considerations. However, it only considers the use of high performance manmade fibre such as aramid, alkali resistant (AR) glass, carbon and polyparaphenylenebenzobisoxazole (PBO). There has been extensive research on using FRCM to retrofit reinforced concrete and masonry structures in structural level with high performance manmade fibre $[3,4,5]$. Unlike FRP strengthened beam, 
the common failure mode of which is in the existing substrate, delamination at thefibre/matrix interface is commonly observed in FRCM counterparts. That means the excellent mechanicalproperties of high performance manmade fibre is not fully utilised. In addition, the bond properties (theparameters of bond-slip model and critical energy release rate) at the fibre/matrix interface of FRCM arethe governing parameters of the overall performance. Alternatively, natural fibre reinforced cementitiousmatrix (NFRCM) is a potential candidate to provide a green, sustainable and cost effective solution forsome applications, such as retrofitting historic buildings or low-rise masonry structures.

One of the key technical challenges of the development of practical NFRCM is the degradation of naturalfibre in alkaline environment of cementitious matrix. There is extensive research on how to improve thedurability of natural fiber in cementitious matrix [8-13]. However, all research focused onmacroscopic mechanical properties, such as tensile strength and flexural strength of the composite withparticular fibre volume fraction and geometry. The findings are useful for comparison among differentstrategies to improve durability of natural fibre in cementitious matrix but they cannot be directly appliedto design a composite in component level with different fibre volume fraction and geometry. In this paper, the surface morphology, chemical composition and bond properties of different treatment of sisal fibre will be presented. The degradation of sisal fibre will be characterised by direct tensile test and pull-out test with accelerated ageing test.

\section{Treatment of sisal fibre}

Sisal fibre is one of the common natural fibre to be investigated in academia. There are many methods to improve the durability of natural fibre in alkaline cementitious matrix. One of the most promising techniques is to immerse sisal fibre in sodium carbonate solution [9]. The mechanism is to deposit a layer of sodium carbonate on fibre surface. When the treated fibre contacts with Portlandite (calcium hydroxide), it forms a layer of calcium carbonate deposit to prevent further alkaline attack. In [9], the optimal duration of immersion in sodium carbonate solution was 7 days. It is too long for practical applications. In the following work, a simple accelerated method will be presented.

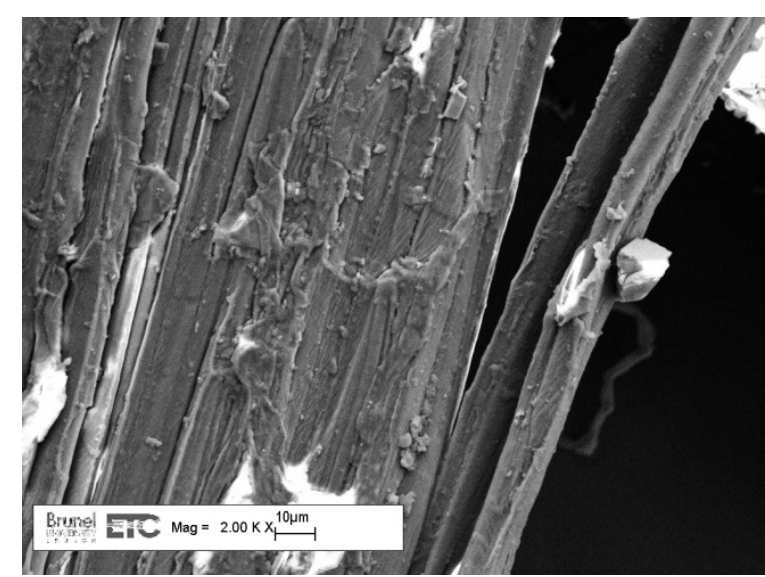

Fig. 1: Micrograph of as-received sisal fibre

Sisal fibre deteriorates in cementitious matrix because of the high alkalinity [11].Fig.1 shows the image of as-received sisal fibre before any treatment under scanning electron microscopy (SEM). It shows relatively smooth surface. The dried fibre is immersed in $1 \mathrm{M}$ sodium carbonate solution at room temperature for 7 days. A layer of deposit is formed on the surface of fibre (Fig. 2). The chemical composition of the deposit is confirmed to be sodium carbonate from energy dispersive X-ray spectroscopy (EDX). When the treated fibre is embedded in cementitious matrix, the sodiumcarbonate deposit reacts with Portlandite and forms a protective layer

of calcium carbonate. As mentioned in [9], the optimal duration of immersion of sisal fibre in sodium carbonate solution is 7 days. When the duration of immersion is shorter, there is not enough sodium carbonate deposit to protect the fibre in alkaline environment. If the duration of immersion is longer, the mechanical properties of the sisal fibre deteriorate significantly due to the alkalinity of sodium carbonate solution. Hence, it is desirable to accelerate the rate of deposition of sodium carbonate to minimise the chance of damaging the fibre in the alkaline sodium carbonate solution.

To accelerate the rate of deposition of sodium carbonate on fibre surface, the as-received sisal fibre is immersed in ethanol solution for 2 hours. Then, the fibre is air dried for one day to evaporate all ethanol from fibre. The ethanol pretreated fibre is immersed in $1 \mathrm{M}$ sodium carbonate solution at room temperature as before. A much denser and uniform deposit is formed on the fibre surface from a SEM image (Fig. 3) and the chemical composition of the deposit is confirmed to be sodium carbonate by EDX. 


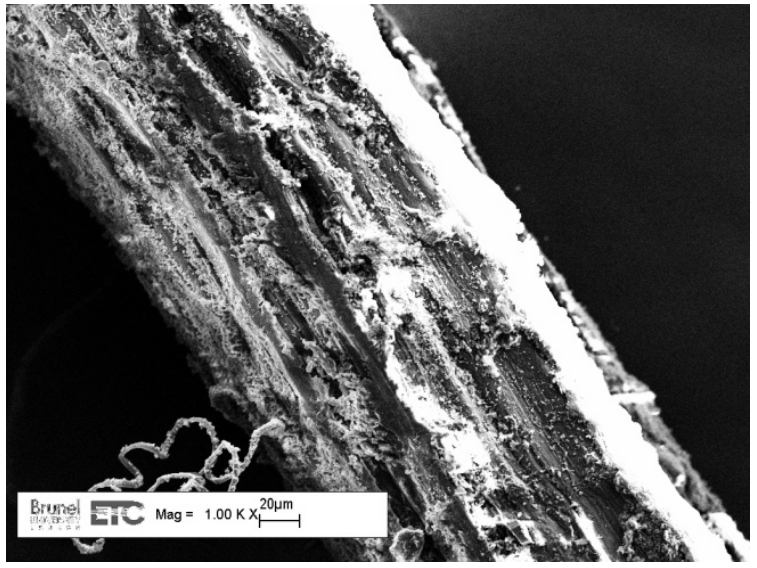

Fig. 2: Micrograph of sisal fibre immersed in $1 M$ sodium carbonate solution for 7 days

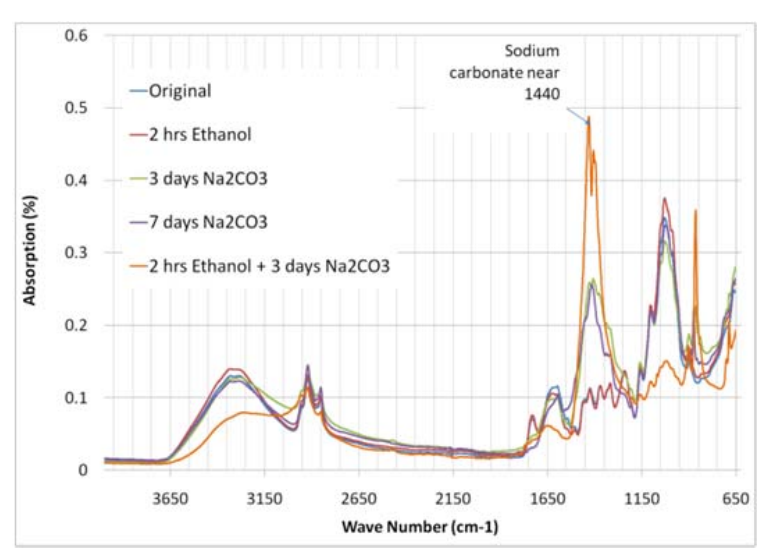

Fig. 4: Fourier transform infrared spectroscopy of as-received,ethanol pretreated, immersion in $1 M$ sodium carbonate for 3 days without ethanol pretreatment, immersion in $1 \mathrm{M}$ sodium carbonate for 7 days without ethanol pretreatment and immersion in $1 M$ sodium carbonate for 3 days with ethanol pretreatment

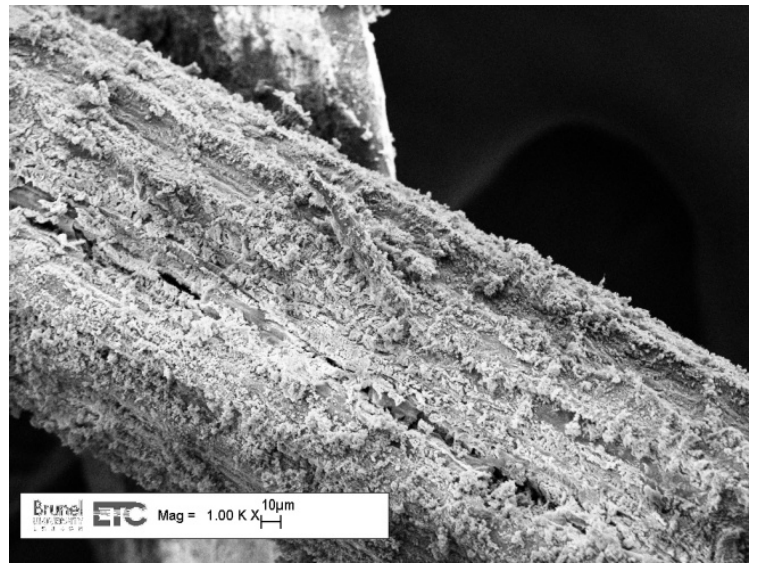

Fig. 3: Micrograph of ethanol pretreated sisal fibre immersed in $1 M$ sodium carbonate solution for 3 days

Fourier transform infrared spectroscopy (FTIR) is used to investigate the change in chemical bond properties (Fig. 4). The FTIR spectra of as-received and ethanol pretreated sisal fibre are identical, which means the ethanol pretreatment does not alter the chemical bond of sisal fibre. The peak near $3300 \mathrm{~cm}^{-1}$ is corresponding to water molecule. When the as-received sisal fibre is immersed in $1 \mathrm{M}$ sodium carbonate solution, there is a very sharp peak formed at $1440 \mathrm{~cm}^{-1}$, which corresponds to sodium carbonate inorganic bond. By comparing the FTIR spectra of as-received sisal fibre immersed in $1 \mathrm{M}$ sodium carbonate solution for 3 days and 7 days are similar. It means that the deposition of sodium carbonate on sisal fibre follow the same mechanism. When immersion duration increases and the duration is not long enough to deteriorate the fibre, the amount of sodium carbonate deposit increases in similar way. For ethanol pretreated sisal fibre immersed in $1 \mathrm{M}$ sodium carbonate solution for 3 days, the peak at $1440 \mathrm{~cm}^{-1}$ is much higher compared to the asreceived sisal fibre immersed in $1 \mathrm{M}$ sodium carbonate solution for 7 days. The peak at $1004 \mathrm{~cm}^{-}$

of ethanol pretreated with immersion of sodium

carbonate solution reduces significantly while there is a new peak formed at $863 \mathrm{~cm}^{-1}$. Since there is no change in the FTIR spectrum of ethanol pretreated fibre before immersing it into sodium carbonate solution, the change in the peaks near $1004 \mathrm{~cm}^{-1}$ and $863 \mathrm{~cm}^{-1}$ is associated with the immersion of ethanol pretreated sisal fibre into $1 \mathrm{M}$ sodium carbonate solution. One possible explanation is that the ethanol activates the site on sisal fibre surface to form new bond between the fibre surface and sodium carbonate deposit. The effectiveness of deposition of sodium carbonate on sisal fibre surface of ethanol pretreated fibre is much higher than as-received counterpart. It can be confirmed by both the SEM image in Fig. 3 and the much higher peak near $1440 \mathrm{~cm}^{-1}$ from the FTIR spectrum in Fig. 4.

\section{Experiments}

\subsection{Direct tensile test}

The elastic modulus and tensile strength of as-received sisal fibre bundle is tested by direct tensile 
test. The elastic modulus is estimated by the slope of the linear portion in the stress-strain curve. The cross-sectional area of fibre bundle is estimated by an image from an optical microscope (Fig. 5). The edge is recognised by software ImageJ and the bounded area is estimated with the scale in the image. The fibre bundle is screwed at two ends around a pulley each side (Fig. 6). The load-displacement curve of tensile test is measured in an Instron machine. The initial gauge length of fibre bundle is $60 \mathrm{~mm}$.

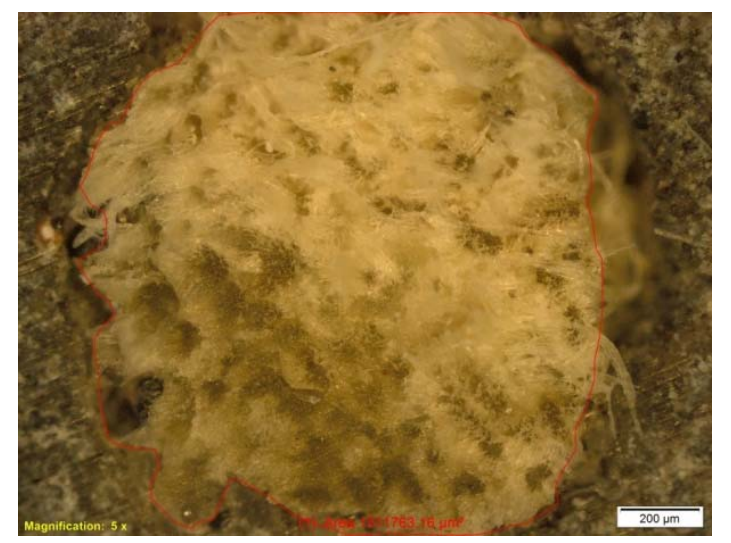

Fig. 5: Cross-section of sisal fibre bundle under optical microscope

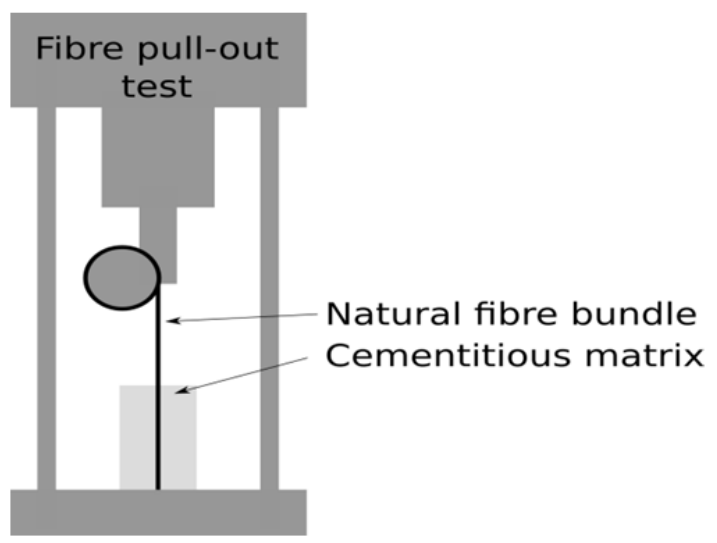

Fig. 6: Schematic diagram of direct tensile test of fibre bundle

\section{Pull-out test}

The as-received sisal fibre bundle is embedded in cementitious matrix with different bond lengths. The mix proportion of the cementitious matrix is cement:water:sand $=1: 0.4: 1$. The cement used for

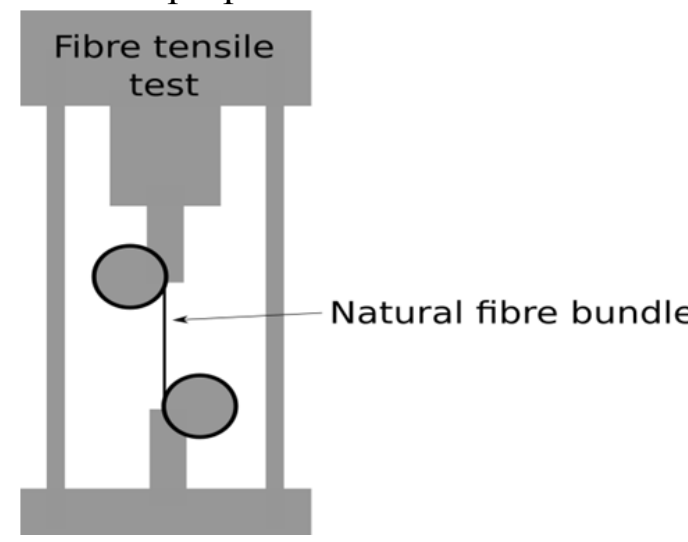

Fig. 7: Schematic diagram of pull-out test of fibre bundle in cementitious matrix the matrix is ordinary Portland cement. The sand used is standard sand (EN 480-13B). The cementitious block is fixed on the Instron loading machine and the fibre bundle is screwed on a pulley (Fig. 7). The load-displacement curve of the pull-out test is recorded by the Instron machine. The gauge length of fibre bundle is $60 \mathrm{~mm}$.

\subsection{Accelerated ageing test}

The degradation of sisal fibre in cementitious matrix is a chemical process. It can be accelerated by elevated temperature. The middle portion of fibre bundle is embedded by cylindrical cementitious matrix with the same mix proportion as in the pull-out test. The asreceived sisal fibre and sisal fibre immersed in $1 \mathrm{M}$ sodium carbonate solution for 7 days without ethanol pretreatment is tested. The samplesare put in an oven at $60^{\circ} \mathrm{C}$ for $7,14,28$ and 35 days after curing at room temperature for 7 days after casting. At 7, 14, 28 and 35 days, direct tensile test and pull-out test are conducted to evaluate the elastic modulus, tensile strength and the bond parameters.

\section{Fracture mechanics model of pull-out test}

For fibre reinforced polymeric matrix composite, for which the ultimate tensile strain of the polymeric matrix is usually larger than that of fibre, the matrix does not crack at ultimate fibre rupture. For fibre reinforced cementitious matrix, the crack strain of matrix is usually lower than fibre rutpure strain. Hence, fibre is pulled out after matrix is cracked. It is crucial to understand the pull-out behaviour of a single fibre bundle to determine the mechanical behaviour of the whole composite. Fig. 8 shows a typical load-displacement curve of a pull-out test. The whole curve can be divided into 3 stages. The first stage is the perfectly bonded stage. The second stage is partially debonded stage. The embedded fibre bundle is partially debonded from the matrix.The final stage is 


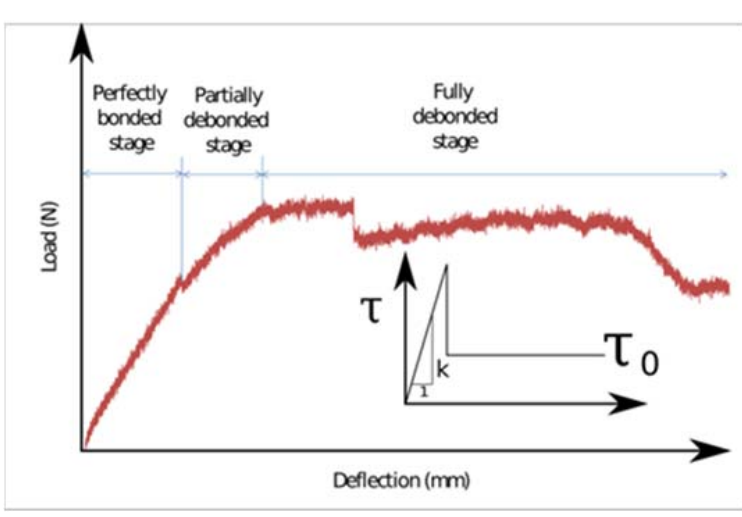

Fig. 8: Typical load-displacement curve of a pull-out test and a linear bond-slip model at the fibre/matrix interface

fully debonded stage and the fibre bundle is pulled out from the matrix. A fracture mechanics model is developed to model the pull-out behaviour of glass fibre bundle [14]. The cross section of fibre bundle is assumed to be circular and the equivalent diameter of fibre bundle is used for the model. The equivalent diameter is defined as the diameter, with which the area of the circle is equal to the area estimated by ImageJ from the image of optical microscope. The bond-slip relation at the fibre/matrix interface is assumed to be linear as shown in the inset of Fig. 8 . There are two bond parameters to characterise the bond properties from the linear bond-slip model. They are $k$ and $\tau_{0}$. With the critical point at the transition between the first and second stage in the load-displacement curve of a pull-out test, the critical energy release rate can be estimated. From the linear portion of the load-displacement curve of a pull-out test, the bond parameter $k$ can be estimated with the known bonded length, equivalent diameter of the cross-sectional area and the elastic modulus of the fibre bundle. From the peak load of the load-displacement curve of a pull-out test, the residual shear stress $\tau_{0}$ of the linear bond-slip model can be estimated. In the following of this paper, the value of $k, \tau_{0}$, elastic modulus and tensile strength will be estimated from direct tensile test and pull-out test of as-received sisal fibre and sisal fibre immersed in $1 \mathrm{M}$ sodium carbonate solution without ethanol pretreatment in cementitious matrix for different duration will be presented.

\section{Results and discussions}

Figs. 9, 10, 11 and 12 show change in time of the tensile strength, elastic modulus, bond modulus $(k)$ and residue shear stress $\left(\tau_{0}\right)$, respectively, of as-received sisal fibre and sisal fibre immersed in $1 \mathrm{M}$

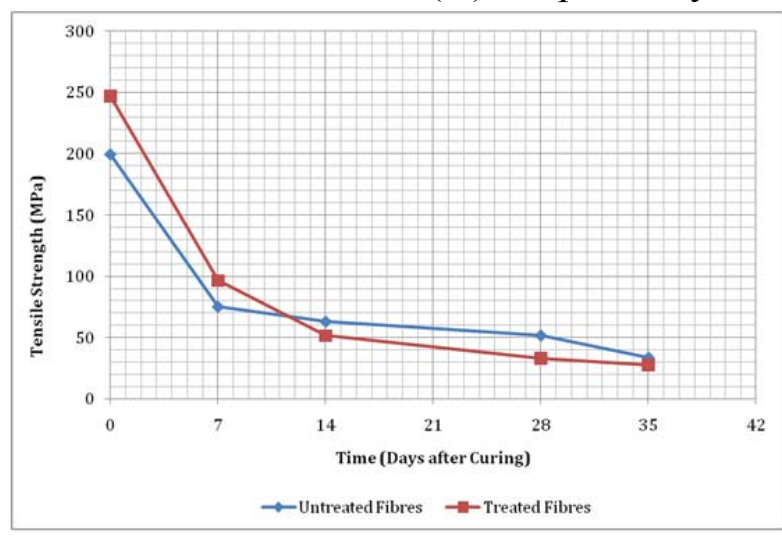

Fig. 9: Change in tensile strength of fibre bundle embedded in cementitious matrix under accelerated ageing test sodium carbonate solution for 7 days without ethanol pretreatment. Day 0 in the graph is corresponding to the time after 7 days room temperature curing from casting. From the results of Fig. 9, the treatment increases the tensile strength significantly but it does not protect the degradation in alkaline environment as expected. There is sharp decrease in tensile strength after a week of exposure of both treated and as-received sisal fibre in cementitious matrix. The degree of reduction in tensile strength follows the same trend of treated and untreated sisal fibre. In Fig. 10, the elastic modulus of treated fibre is much higher than untreated fibre. However, after 7 days of accelerated ageing test, it is reduced lower than the untreated fibre. Hence, in terms of mechanical properties of tensile strength and elastic modulus, the immersion of sisal fibre in $1 \mathrm{M}$ sodium carbonate at room temperature is not an effective way to protect sisal fibre in cementitious matrix with high alkalinity. In long term, there is no significant difference in tensile strength and elastic modulus in cementitious matrix.

In Fig. 11, the bond modulus $(k)$ does not change for the treated fibre while there is significant increase between the $14^{\text {th }}$ day and $28^{\text {th }}$ day. It indicates no significant change at the fibre surface of treated fibre of bonded fibre. In Fig. 12, the residual shear strength $\left(\tau_{0}\right)$ at the fibre/matrix interface after debonding of treated fibre reduces significantly in the first 7 days but it is stabilised afterwards. For the untreated fibre, the residual shear strength fluctuated that indicates the surface properties vary with time and chemical degradation probably occurs at the fibre/matrix interface. 


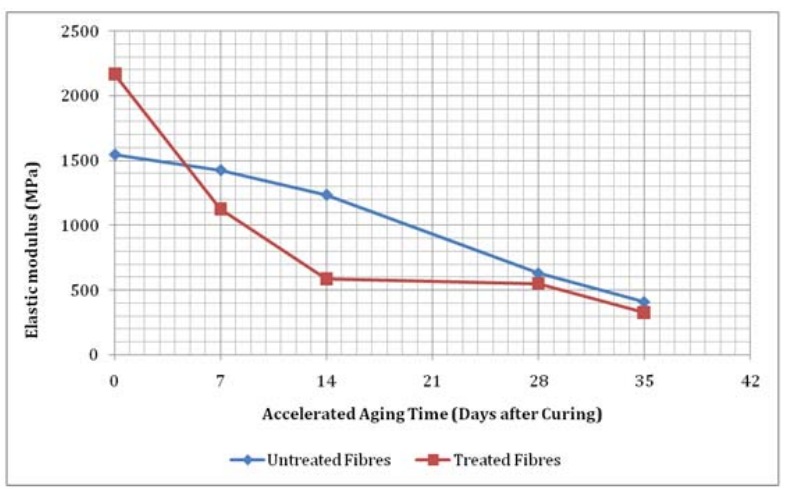

Fig. 10: Change in elastic modulus of fibre bundle embedded in cementitious matrix under accelerated ageing test

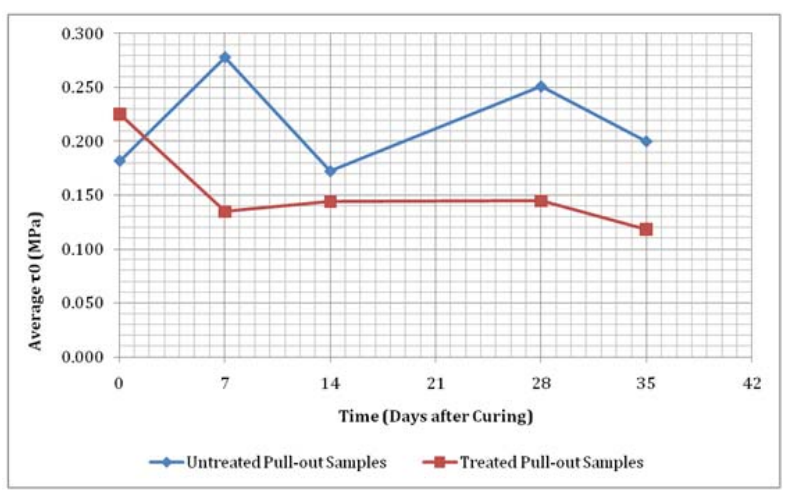

Fig. 12: Change in residual shear strength of fibre bundle embedded in cementitious matrix under accelerated ageing test

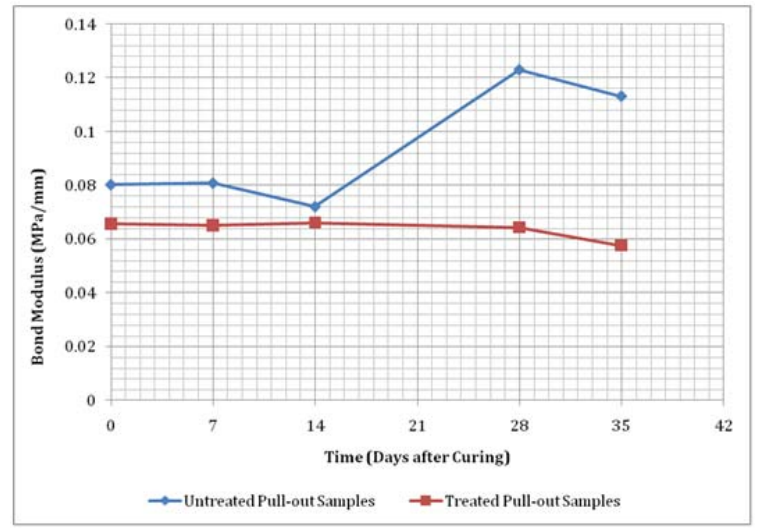

Fig. 11: Change in bond modulus of fibre bundle embedded in cementitious matrix under accelerated ageing test

Overall, although the treated fibre shows significant reduction in tensile strength and elastic modulus as the untreated fibre in accelerated ageing test, the surface properties are relatively much more stable. It means that the treatment can reduce degradation of fibre on the surface. The key issue of the ineffectiveness of the immersion of sisal fibre in sodium carbonation solution is because the deposition of sodium carbonate is not uniform and dense enough and hence the protective calcium carbonate layer is not dense enough to stop further alkaline attack to inner fibre threads.

\section{Conclusions}

In this paper, the morphology, chemical composition and chemical bonding properties of asreceived sisal fibre, sisal fibre immersed in sodium carbonate solution with and without ethanol pretreatment at fibre surface are characterised by scanning electron microscopy, energy dispersive X-ray spectroscopy and Fourier transform infrared spectroscopy, respectively. The tensile strength, elastic modulus and the bond parameters at fibre/matrix interface of as-received sisal fibre as well as sisal fibre immersed in $1 \mathrm{M}$ sodium carbonate solution without ethanol pretreatment at different stages of degradation in cementitious matrix is evaluated by direct tensile test and pull-out test. It is found that the degradation of tensile strength and elastic modulus of treated and untreated fibre is similar while the bond parameters of treated fibre is much more stable compared to untreated fibre. It can be concluded the treated is effective on the surface but the protective layer is not dense enough to prevent further alkaline attack to inner fibre without ethanol pretreatment. In the presentation, the test results of tensile strength, elastic modulus and bond parameters of sisal fibre immersed in $1 \mathrm{M}$ sodium carbonate solution for 3 days with ethanol pretreatment will be presented.

\section{Acknowledgments}

The research for this paper was financially supported by the BRIEF Award of Brunel University London. 


\section{References}

[1] BURDEN E., LOW Z., BIANCHI P., and TAN S.M., "Reinforced Concrete Dimensioning based on Element Nodal Forces", ASCE Journal of Structural Engineering, Vol. 120, No. 6, 2002, pp. 1718-1731.

[2] SMITH L., Limit Analysis and Concrete Plasticity, Prentice Hall, New York, 2003, p. 360.

[3] A. C. 549, ACI 549.4R-13: Guide to Design and Construction of Externally Bonded Fabric Reinforced Cementitious Matrix (FRCM) Systems for Repair and Strengthening Concrete and Masonry Structures, American Concrete Institute.

[4] AC434, Masonry and Concrete Strengthening Using Fiber-reinforced Cementitious Matrix (FRCM) Composite Systems, ICC-ES.

[5] Faella C., Martinelli E., Nigro E., Paciello S., "Shear capacity of masonry walls externally strengthened by a cement-based composite material: An experimental campaign", Construction and Building Materials, Vol. 24, No. 1, 2010, pp. 84-93.

[6] D’Ambrisi A., Feo L., Focacci F., "Experimental analysis on bond between PBO-FRCM strengthening materials and concrete", Composites Part B: Engineering, Vol. 44, No. 1, 2013, pp. 524-532.

[7] D'Ambrisi A., Feo L., Focacci F., "Experimental and analytical investigation on bond between carbon-frcm materials and masonry", Composites Part B: Engineering, Vol. 46, 2013, pp. 15-20.

[8] Ardanuy M., Claramunt J., Toledo Filho R. D., "Cellulosic fiber reinforced cement-based composites: A review of recent research", Construction and Building Materials, Vol. 79, 2015, pp. 115-128.

[9] Wei J., Meyer C., "Improving degradation resistance of sisal fiber in concrete through fiber surface treatment", Applied Surface Science, Vol. 289, 2014, pp. 511-523.

[10] Pereira C. L., Savastano H., Pay J., S. Santos F., Borrachero M. V., Monz J., Soriano L., "Use of highly reactive rice husk ash in the production of cement matrix reinforced with green coconut fiber", Industrial Crops and Products, Vol. 49, 2013, pp.88-96.

[11] Filho J. D. A. M., Silva F. D. A., Toledo Filho R. D., "Degradation kinetics and aging mechanisms on sisal fiber cement composite systems", Cement and Concrete Composites, Vol 40, 2013, pp.30-39.

[12] Tonoli G. H. D., Rodrigues Filho U. P., Savastano Jr. H., Bras J., Belgacem M. N., Rocco Lahr F. A., "Cellulose modified fibres in cement based composites", Composites Part A: Applied Science and Manufacturing, Vol. 40, No.12, 2009, pp. 2046-2053.

[13] De Jesus Nagahama K., De Souza Matos Gada A., Lima P. R. L., "Finite strip modeling of cementitious laminates reinforced with sisal fibers", Cement and Concrete Composites, Vol. 63, 2015, pp. 8-16.

[14] X. B. Zhang, H. Aljewifi, J. Li, "Failure behaviour investigation of continuous yarn reinforced cementitious composites", Construction and Building Materials, Vol. 47, 2013, pp. 456-464. 